\title{
Anti-bacterial Activity of Polyvinyl Pyrrolidone Capped Silver Nanoparticles on the Carbapenem Resistant Strain of Acinetobacter baumannii
}

\author{
Vishvanath Tiwari ${ }^{1 *}$, Manoj Kumar Khokar', Monalisa Tiwari' ${ }^{1}$, Swati Barala² and Manish Kumar ${ }^{2}$ \\ ${ }^{1}$ Department of Biochemistry, Central University of Rajasthan, Ajmer-305817, India \\ ${ }^{2}$ Department of Physics, Central University of Rajasthan, Ajmer-305817, India
}

\begin{abstract}
Acinetobacter baumannii has been identified by Infectious Diseases Society of America as one of the six pathogens that cause majority of hospital infections. Carbapenems are the most effective $\beta$-lactam antibiotics that are routinely prescribed by clinicians to patients infected with $A$. baumannii. Emergence of resistance against carbapenem makes it difficult to treat $A$. baumannii hence it is a threat to public health. Therefore it is very important to find a suitable alternative to the carbapenem. In the present work we have tried to establish silver nanomaterial as an alternative to carbapenem resistant strain of Acinetobacter baumannii. Silver nanoparticles have been prepared without aggregation by a modified chemical reduction method; using ethylene glycol mono methyl ether as solvent and polyvinyl pyrrolidone (PVP) as capping agent. Transmission electron microscopic study revealed silver nanoparticles in spherical shape with narrow size distribution. The average size of silver nanoparticles has varied by changing the metal precursor to capping agent ratio, and corresponding characteristic size dependent plasmonic properties were observed using UVVis spectroscopy. It was found that novel silver nanoparticles having particle diameter $<10 \mathrm{~nm}$ exhibited a tremendous potential antibacterial activity against the carbapenem resistant strain of Acinetobacter baumannii. Therefore, PVPcapped silver nanoparticle can be developed as an alternative to carbapenem, the most prescribed antibiotic for the Acinetobacter baumannii infections.
\end{abstract}

Keywords: PVP-capped silver nanoparticles; Carbapenem resistance; Acinetobacter baumannii; Silver nanoparticles; Carbapenem

\section{Introduction}

Acinetobacter baumannii causes pneumonia, urinary tract infections, respiratory infections and meningitis [1]. Due to its pathogenicity, it is grouped into ESKAPE pathogens, a group of pathogens causing hospital-acquired infections $[1,2]$. A. baumannii has emerged as a threat to soldiers, wounded during military operations in Iraq and Afghanistan [3] as well as isolated from natural resources [4]. It can grow on artificial surfaces and can utilize ethanol as a carbon source [5], resist desiccation, survive at diverse temperatures and $\mathrm{pH}$ [6]. Prevalence of A. baumannii in clinical setup increases gradually $[7,8]$. Commonly prescribed drug against A. baumannii are carbapenems which belongs to the $\beta$-lactam group of antibiotics [9]. A. baumannii has developed resistance against carbapenem using very diverse mechanisms [10-18] which is a significant health problem and responsible for high morbidity and mortality [19]. Mortality due to carbapenem-resistant Acinetobacter baumannii is about $52 \%$ as compared to $19 \%$ when infected with carbapenem sensitive variant [20]. Therefore, there is an urgent need to find the suitable alternative for carbapenem.

Silver is one of the most universal antimicrobial substances. Nanoengineering enables us to expand the surface area of silver particles markedly. Silver nanoparticles have shown antimicrobial activity against a wide array of microbes, probably due to their multiple mechanisms of antimicrobial action [21]. Contrary to bactericide effects of ionic silver, the antimicrobial activities of colloid silver particles are influenced by the morphology of the silver particles. Therefore, in developing synthesis methodologies, emphasis should be given to control the size, shape, size distribution and local distribution of silver nanoparticles. Silver nanoparticles have been produced using different methods: thermal decomposition [22,23], swift heavy ion irradiation [24], atom beam irradiation [25], electron beam physical vapour co- deposition [26] and chemical reduction method [27]. In the present article we have employed the chemical method. Small nanoparticles with a large surface area to volume ratio provide a more efficient means for antibacterial activity even at very low concentrations [28].

Antibacterial activity of silver nanoparticles (Ag-NPs) in dispersed state as well as in embedded state has been reported for their antibacterial activity against different bacteria i.e. Pseudomons aeruginosa (ATCC17934), Staphylococcus aureus (ATCC-25923), Escherichia coli (ATCC 25922), Enterobacter cloacae (ATCC 29249) [29-33]. Silver and other nanoparticles are reported to interact with certain proteins and thereby showed its activity [34]. There are few reports which initiated the research of silver nanomaterial as an antimicrobial agent for Acinetobacter baumannii $[28,35]$. Niakan et al., identified that selected bacterial strains of $A$. baumannii are sensitive to silver (uncapped) nanomaterial [28]. Capped silver nanoparticles (like citrate-capped, SDS-capped) have also been synthesised against Gram negative bacteria [36-38]. Similarly, Huang et al., identified the antimicrobial activity of AgNPs against A. baumannii by synergistic combination of chitosan acetate with silver nanoparticle [35]. Antimicrobial activity of PVP capped Ag-NPs have been determined only for few bacteria like Salmonella, S. aureus and E. coli $[37,38]$. However, the antimicrobial

*Corresponding author: Vishvanath Tiwari, Department of Biochemistry, Central University of Rajasthan, Ajmer- 305817, India, Tel: 91-1463-238652; Fax: 911463-238722; E-mail: vishvanath7@yahoo.co.in

Received October 31, 2014; Accepted November 17, 2014; Published November 27, 2014

Citation: Tiwari V, Khokar MK, Tiwari M, Barala S, Kumar M (2014) Anti-bacteria Activity of Polyvinyl Pyrrolidone Capped Silver Nanoparticles on the Carbapenem Resistant Strain of Acinetobacter baumannii. J Nanomed Nanotechnol 5: 246. doi: 10.4172/2157-7439.1000246

Copyright: ( 2014 Tiwari V, et al. This is an open-access article distributed under the terms of the Creative Commons Attribution License, which permits unrestricted use, distribution, and reproduction in any medium, provided the original author and source are credited. 
Citation: Tiwari V, Khokar MK, Tiwari M, Barala S, Kumar M (2014) Anti-bacterial Activity of Polyvinyl Pyrrolidone Capped Silver Nanoparticles on the Carbapenem Resistant Strain of Acinetobacter baumannii. J Nanomed Nanotechnol 5: 246. doi: 10.4172/2157-7439.1000246

Page 2 of 6

activity of the polyvinyl pyrrolidone (PVP) capped Ag-NPs has not studied so far on Acinetobacter baumannii. PVP is a neutral organic stabilizer and is less sensitive to the surface charge screening processes by ionic strength as compared to citrate [37]. Retention of PVP coated AgNP is more than citrate coated AgNP because particle size of PVP coated nanoparticles is less sensitive to changes in $\mathrm{pH}$ and ionic strength $[37,39,40]$. Recent report showed that PVP capped Ag-NPs are more stable than other AgNPs like citrate AgNPs and SDS AgNPs $[37,38]$ hence PVP capped AgNPs is less toxic for mammalian cells [41] therefore PVP capped AgNPs can be more favorable as an alternative drug to carbapenem as compared to other capped AgNPs. Similarly, interaction of AgNPs with serum proteins also affects its antimicrobial activity in-vivo. It is also reported that PVP-capped AgNPs showed better antimicrobial activity than other capped AgNPs in-vivo [42]. Therefore, it is important to study antimicrobial activity of PVP capped AgNPs on carbapenem resistant strain of Acinetobacter baumannii. The present result will help to demonstrate the antibacterial properties of the PVP capped AgNPs against carbapenem resistance strain of Acinetobacter baumannii.

\section{Methods}

\section{Preparation of the PVP-capped silver nanoparticle (Ag-NPs)}

For the size dependent properties of silver nanoparticles, colloidal suspension of silver nanoparticles were prepared using modified chemical decomposition method. In this method, we started with $0.1 \mathrm{~N}$ $\mathrm{AgNO}_{3}$ as metal precursor, polyvinyl pyrrolidone (PVP) as a capping agent (powder form with average molecular weight of 29000) and $97 \%$ ethylene glycol mono methyl ether $\left(\mathrm{CH}_{3} \mathrm{OCH}_{2} \mathrm{CH}_{2} \mathrm{OH}\right)$ as a solvent (All chemicals procured from Sigma-Aldrich). Firstly, $5 \mathrm{ml}$ of $\mathrm{AgNO}_{3}$ was dissolved in $10 \mathrm{ml}$ of ethylene glycol mono methyl ether and stirred for $2 \mathrm{~h}$, kept in temperature range $40-50^{\circ} \mathrm{C}$. After this step, appropriate amount of PVP was added in this solution to maintain different metal to capping agent ratio. Stirring was continued further for $30 \mathrm{~min}$ and a yellow solution of Ag colloids was obtained. In Table 1, the amount of precursor, solvent and capping agent that was taken to prepare silver nanoparticle and corresponding physical appearance of colloidal solutions has been presented.

\section{Characterization of the PVP-capped silver nanoparticle}

Silver nanoparticle was characterised by the transmission electron microscope [2] and UV-Vis spectroscopy. For TEM study, colloidal particles are first dispersed at carbon coated mica sheet, and then carbon coating is floated on $\mathrm{Cu}$ grid. Then, these grids were investigated using an electron microscope (FEI Tecnai 20) operated at $100 \mathrm{keV}$ beam energy. For investigating the plasmonic properties of colloidal silver nanoparticles, double beam UV-Vis spectrophotometer (Hitachi U3300) was carried out in spectral range of 200 to $800 \mathrm{~nm}$ taking solvent as reference.

\begin{tabular}{|c|c|c|c|c|c|}
\hline $\begin{array}{c}\text { Sample's } \\
\text { name }\end{array}$ & $\begin{array}{c}\text { Amount } \\
\text { of metal } \\
\text { precursor } \\
\left(\mathrm{AgNO}_{3}\right)\end{array}$ & $\begin{array}{c}\text { Amount } \\
\text { of Solvent } \\
\left(\mathrm{CH}_{3} \mathrm{OCH}_{2} \mathrm{CH}_{2} \mathrm{OH}\right)\end{array}$ & $\begin{array}{c}\text { Amount of } \\
\text { capping } \\
\text { agent (PVP) }\end{array}$ & $\begin{array}{c}\text { Physical } \\
\text { appearance } \\
\text { (Color) }\end{array}$ & $\begin{array}{l}\text { Size of } \\
\text { Ag NPs }\end{array}$ \\
\hline A0 & $5 \mathrm{ml}(0.1 \mathrm{~N})$ & $10 \mathrm{ml}(97 \%)$ & $0.025 \mathrm{gm}$ & Gray & - \\
\hline A1 & $5 \mathrm{ml}(0.1 \mathrm{~N})$ & $10 \mathrm{ml}(97 \%)$ & $0.05 \mathrm{gm}$ & Dark Yellow & $10 \pm 2 \mathrm{~nm}$ \\
\hline A2 & $5 \mathrm{ml}(0.1 \mathrm{~N})$ & $10 \mathrm{ml}(97 \%)$ & $0.1 \mathrm{gm}$ & Yellow & $8 \pm 2 \mathrm{~nm}$ \\
\hline A3 & $5 \mathrm{ml}(0.1 \mathrm{~N})$ & $10 \mathrm{ml}(97 \%)$ & $0.2 \mathrm{gm}$ & Light & $6 \pm 2 \mathrm{~nm}$ \\
\hline
\end{tabular}

Table 1: Colloidal silver nanoparticle solution having different concentration of polyvinyl pyrrolidone.

\section{Clinical strains of Acinetobacter baumanni}

Clinical strains of Acinetobacter baumannii were taken from department of biochemistry, A.I.I.M.S., India. All clinical strains were isolated from sputum of patients admitted to Intensive Care Units (ICUs), A.I.I.M.S., India. All clinical strains were confirmed up to the species level (baumannii) by standard biochemical tests [8]. Four clinical strains (RS307, RS122, RS6694 and RS6053) of Acinetobacter baumannii are used in the present study.

\section{Antimicrobial susceptibility testing and minimum Inhibitory concentration testing for carbapenem}

Antimicrobial susceptibility test measures the ability of an antibiotic or other antimicrobial agent to inhibit bacterial growth in-vitro. Antimicrobial discs of the above drugs were prepared. After adjustment of an inoculum size, the inoculum was swabbed uniformly on Muller-Hinton Agar plate with the help of a sterile cotton swab where excess inoculum was removed after pressing the swab lightly on the inside wall of the test tube. After $15 \mathrm{~min}$ of swabbing, the antibiotic discs were carefully placed with the help of sterile forceps. After 5-10 $\mathrm{min}$, the plates were incubated at $37^{\circ} \mathrm{C}$. The inhibition zone against antibiotic discs was observed and interpreted as sensitive (S) or resistant (R) according to standards laid by CLSI. Minimal inhibitory concentration of clinical strains was determined for imipenem (a carbapenem) by agar dilution method under the CLSI guideline according to our previously described method [8].

\section{Growth kinetics of resistance strain of the Acinetobacter} baumannii under diverse condition of silver nanoparticle

Growth kinetics of different carbapenem resistant strains of $A$. baumannii have been determined by taking O.D. of different strain of Acinetobacter at $605 \mathrm{~nm}$ with the time using ELISA reader as well as UV-Vis spectroscopy. Growth curve has been prepared from the absorption data. The stock solution of silver nanoparticle with concentration of $33 \mathrm{mM}$ was used and the final working concentration of silver nanoparticle was $165 \mu \mathrm{M}$. The experiments were repeated in the absence and presence of silver nanoparticle. The relative growth curve has been prepared for the comparison purpose.

\section{Results and Discussion}

To study the effects of silver nanomaterial on the carbapenem resistant strain of Acinetobacter baumannii. First step is the synthesis and characterisation of silver nanoparticle. This step is followed by antimicrobial testing of silver nanoparticle on the carbapenem resistant strain of Acinetobacter baumannii.

\section{Characterization of polyvinyl pyrrolidone (PVP) capped nanoparticles}

Transmission electron microscope is used to characterize silver nanoparticle. Figure 1 shows the representative micrograph of PVP capped Ag nanoparticles. From the TEM micrograph, it is evident that prepared nanoparticles were in spherical shape and uniformly distributed without any agglomeration. Their diameters were found in the range of 6-10 $\mathrm{nm}$. For investigating the plasmonic properties of colloidal silver nanoparticles, UV-Vis spectroscopy was carried out in spectral range of 200 to $800 \mathrm{~nm}$. The optical absorbance spectra of the colloidal silver nanoparticles are shown in Figure 2, where curves (a), (b), (c) and (d) are corresponding to the samples A0, A1, A2 and A3 prepared with capping amount PVP as $0.025 \mathrm{gm}, 0.05 \mathrm{gm}, 0.1 \mathrm{gm}$ and 0.2 gm respectively. For all curves, two dominant peaks are observed; 


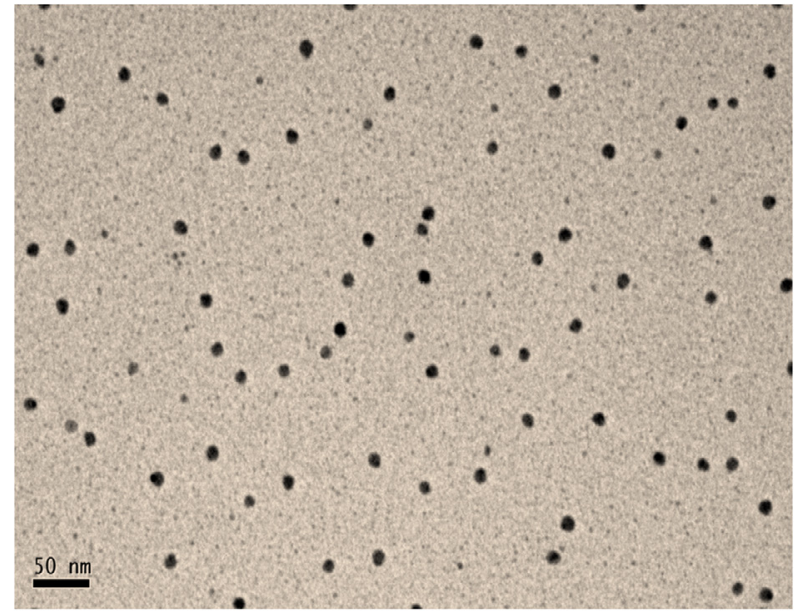

Figure 1: Representative PVP capped silver nanoparticles.

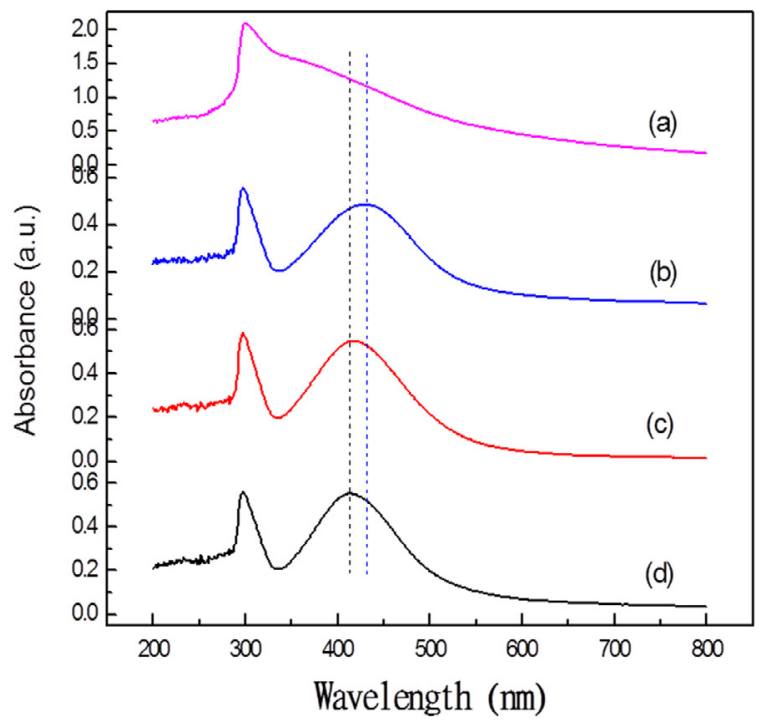

Figure 2: The optical absorbance spectra of the colloidal silver nanoparticles are shown, where curves (a), (b), (c) and (d) are corresponding to the samples $A 0, A 1, A 2$ and $A 3$ prepared with capping amount PVP as $0.025 \mathrm{gm}$, $0.05 \mathrm{gm}, 0.1 \mathrm{gm}$ and $0.2 \mathrm{gm}$; respectively.

first peak centered at $296.65 \mathrm{~nm}$ and second peak centered in range from $412-431 \mathrm{~nm}$. The first peak in spectrum is assigned to $\mathrm{NO}_{3}^{-}$ions while second significant peaks centered in range from $412-431 \mathrm{~nm}$ provide clear evidence for the formation of silver nanoparticles. When silver nanoparticles are irradiated by visible radiation then surface plasmon resonance [43] occurs and provides absorbance peak in these wavelength regions. A decrease in full width at half maximum (FWHM) suggests an increase in silver nanoparticle core-diameter [44]. The broad plateau of A0 in wavelength region of $340-540 \mathrm{~nm}$ is an indication of agglomerated silver nanoparticles with wide size distribution, which suggests that amount of capping agent was too small to confine silver particle in monomodal nanoscale sizes. The characteristic peaks of silver nanoparticles in A1, A2 and A3 samples show narrow FWHM, which shows that average size distribution of silver nanoparticles is very small. This result is in agreement with the microscopic image shown in
Figure 1. The observed blue shift in this characteristic absorption peak from $431 \mathrm{~nm}$ to $412 \mathrm{~nm}$ is an indication of decrease in average particle sizes of silver nanoparticles, when we move from A1 to A2 and then further to A3. It also explains the PVP capping stabilizes the Ag-NPs [38]. The assignment of the absorption peaks are in agreement with other reported values in literature. Gasaymeh et al. reported $\mathrm{NO}_{3}$ peak at $256 \mathrm{~nm}$ [45]. Kumar et al. reported SPR peak of silver nanoparticle after adding $\mathrm{NaBH}_{4}$ in aqueous solution at $389-402 \mathrm{~nm}$ corresponding to average nanoparticle size in $4 \mathrm{~nm}-10 \mathrm{~nm}$ and around $454 \mathrm{~nm}$ when $\mathrm{Ag}$ nanoparticles of average size $14 \mathrm{~nm}$ were embedded in $\mathrm{ZrO}_{2}$ matrix $[27,46]$. Therefore the size of the PVP capped AgNPs is about 5 to $15 \mathrm{~nm}$. The intermediate spectral location of the silver nanoparticles in present case is because of intermediate refractive index of solvent (1.43) in comparison to that of $\mathrm{H}_{2} \mathrm{O}(1.33)$ and $\mathrm{ZrO}_{2}(\sim 2)$. The fine assignment of peaks can also be done using effective medium theories and considering the refractive indices of solvent as well as of capping layer along with the size dependent dielectric functions of silver. PVP capping on the surface of nanoparticles protects from changes in environmental conditions and prevents aggregation [38]. With these results, inference can be drawn that prepared silver nanoparticles, using PVP amount in range of $0.05 \mathrm{gm}$ to $0.2 \mathrm{gm}$, were found spherical shaped, agglomeration-free and with narrow size distribution except by $0.025 \mathrm{gm}$. The prepared PVP capped silver particles A1, A2 \& A3 have been used for the antimicrobial test.

\section{Antimicrobial susceptibility test}

This test was carried out in presence of various antibiotics namely amikacin, meropenem, imipenem, piperacillin, netlimycin, ciprofloxacine, aztreonam, ceftazidime, [pipracillin + tazo-bactam], [cefoperazone + sulbactam] and [ticarcillin + clavulanic acid], [amoxicillin + clavulinic acid]. Table 2 summarizes the result of the test for the selected four strains of A. baumannii. The data reveals that all the strains are resistant to most of the antibiotics that are usually used in clinical treatment. Only combination of $\beta$-lactams drugs with $\beta$-lactamase inhibitors have shown a slight potency in antimicrobial activity. All these A. baumannii strains also showed resistance against other groups like fluoroquinolones and aminoglycosides. The MIC of the strains for imipenem, a carbapenem has also been determined. Four resistant strains RS307, RS122, RS6053 and RS6694 have minimal inhibitor concentration of $64 \mu \mathrm{g} / \mathrm{ml}, 32 \mu \mathrm{g} / \mathrm{ml}, 8 \mu \mathrm{g} / \mathrm{ml}$ and $8 \mu \mathrm{g} / \mathrm{ml}$ respectively for carbapenem. Based on CLSI guidelines, RS307 is high

\begin{tabular}{|l|c|c|c|c|}
\hline Strain no. & RS307 & RS122 & RS6053 & RS6694 \\
\hline Amikacin & $\mathrm{R}$ & $\mathrm{R}$ & $\mathrm{R}$ & $\mathrm{R}$ \\
\hline Meropenem & $\mathrm{R}$ & $\mathrm{R}$ & $\mathrm{R}$ & $\mathrm{R}$ \\
\hline Imipenem & $\mathrm{R}$ & $\mathrm{R}$ & $\mathrm{R}$ & $\mathrm{R}$ \\
\hline Pipracillin & $\mathrm{R}$ & $\mathrm{R}$ & $\mathrm{R}$ & $\mathrm{R}$ \\
\hline Netlimycin & $\mathrm{R}$ & $\mathrm{R}$ & $\mathrm{R}$ & $\mathrm{R}$ \\
\hline Ciprofloxacine & $\mathrm{R}$ & $\mathrm{R}$ & $\mathrm{R}$ & $\mathrm{R}$ \\
\hline Aztreonam & $\mathrm{R}$ & $\mathrm{R}$ & $\mathrm{R}$ & $\mathrm{R}$ \\
\hline Ceftazidime & $\mathrm{R}$ & $\mathrm{R}$ & $\mathrm{R}$ & $\mathrm{R}$ \\
\hline Amoxacillin + Clavulinic acid & $\mathrm{R}$ & $\mathrm{R}$ & $\mathrm{S}$ & $\mathrm{S}$ \\
\hline Pipra + Tazobactum & $\mathrm{R}$ & $\mathrm{R}$ & $\mathrm{S}$ & $\mathrm{S}$ \\
\hline Cefope + Sulbacum & $\mathrm{R}$ & $\mathrm{S}$ & $\mathrm{S}$ & $\mathrm{S}$ \\
\hline Ticarcillin + Calvulanic acid & $\mathrm{R}$ & $\mathrm{R}$ & $\mathrm{S}$ & $\mathrm{S}$ \\
\hline MIC for Imipenem & $64 \mu \mathrm{g} / \mathrm{ml}$ & $32 \mu \mathrm{g} / \mathrm{ml}$ & $8 \mu \mathrm{g} / \mathrm{ml}$ & $8 \mu \mathrm{g} / \mathrm{ml}$ \\
\hline (Carbapenem) & & & & \\
\hline Resistance level & High & Intermediate & Intermediate & Intermediate \\
\hline
\end{tabular}

Table 2: Antibiotic sensitivity test using various antibiotics for carbapenem resistant strains and MIC for the Imipenem. 
Citation: Tiwari V, Khokar MK, Tiwari M, Barala S, Kumar M (2014) Anti-bacterial Activity of Polyvinyl Pyrrolidone Capped Silver Nanoparticles on the Carbapenem Resistant Strain of Acinetobacter baumannii. J Nanomed Nanotechnol 5: 246. doi: 10.4172/2157-7439.1000246

resistance while RS122, RS6053 and RS6694 are intermediate resistance to carbapenem.

\section{Differential growth kinetics of resistance strain of the Acinetobacter baumannii in the absence and presence of silver nanoparticle}

After characterizations the nanomaterials (A1, A2 and A3) were further used to study the antimicrobial activity of the PVP capped silver nanoparticles on high resistant strains of Acinetobacter baumannii (RS307). The resistant strains of Acinetobacter baumannii was cultured at different silver nanoparticle prepared at different conditions and growth of the bacterium is monitored by ELISA reader. The result showed that there is a difference in the effect of different silver nanomaterial on the bacterial growth that means effectiveness of silver nanoparticle change with the change in the method of preparation. Figure 3 showed the effect of three types of silver nanomaterial (A1, A2, A3) on the growth of the carbapenem resistant strains of Acinetobacter baumannii. The experiment was run in triplicate and presented value in Figure 3 is the average of three. Although the A1 and A2 nanoparticles have similar inhibitory effect but A3 showed slightly higher antimicrobial activity. We found that among three nanomaterial's, A3 has more inhibitory effect therefore A3 nanomaterial has been selected for the further studies. PVP concentration was highest in A3 nanoparticle which also enlightens that the highly PVP-capped AgNPs have better reliability in terms of antimicrobial activity as compared to less PVP capped AgNPs.

Antimicrobial activity of silver nanoparticle on different strain of Acinetobacter baumannii with diverse resistance level

The effects of highly PVP capped AgNPs (A3) on different resistant strains of Acinetobacter baumannii with different carbapenem resistance level have also been studied. Selected four carbapenem resistant strains RS307, RS122, RS6053 and RS6694 with the minimal inhibitor concentration of $64 \mu \mathrm{g} / \mathrm{ml}, 32 \mu \mathrm{g} / \mathrm{ml}, 8 \mu \mathrm{g} / \mathrm{ml}$ and $8 \mu \mathrm{g} / \mathrm{ml}$ respectively for carbapenem were used for the present study. The results of antimicrobial activity of A3 Ag-NPs on different strains of Acinetobacter baumannii are shown in Figures 4-6. The experiment is performed by taking absorbance at $605 \mathrm{~nm}$ using UV-Vis Spectroscopy. There are differences in the absorption maximum between different

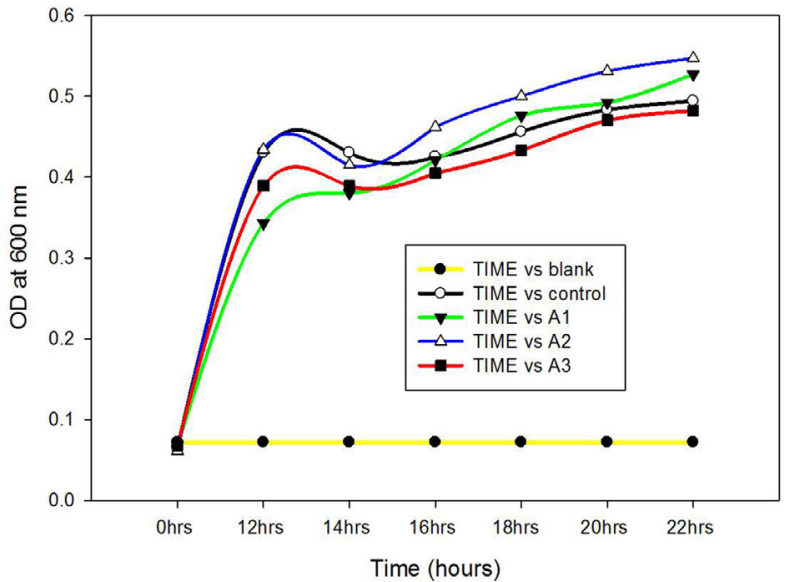

Figure 3: Comparative study on antimicrobial activities of three Ag-NPs (A1, A2 \& A3) on the carbapenem resistant strain of Acinetobacter baumannii.

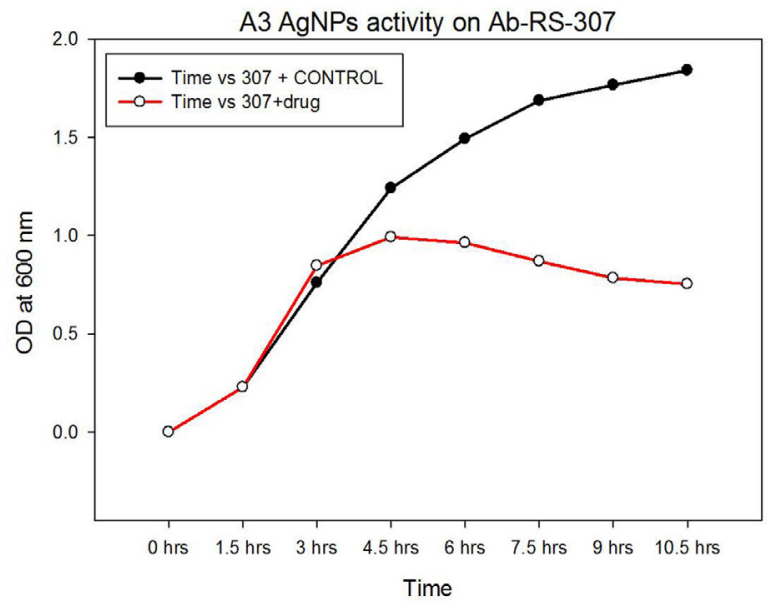

Figure 4: Graphical representation of Antimicrobial activity of A3 Ag-NPs on the resistant strain 307 of Acinetobacter baumannii.

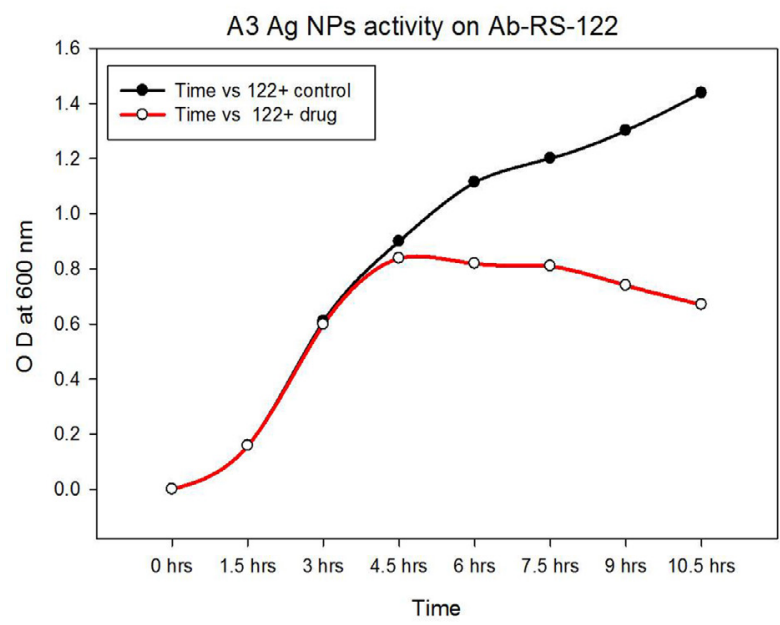

Figure 5: Graphical representation of Antimicrobial activity of A3 Ag-NPs on the resistant strain 122 of Acinetobacter baumannii.

clinical strains (Figures 4-6) which showed the difference in growth kinetics of different carbapenem resistant strains of A. baumannii. Absorption maximum determined using ELISA (Figure 3 ) and UV-Vis Spectroscopy (Figure 4) are different but pattern of growth remains same. The PVP capped AgNPs (A3) have antibacterial activity on all the clinical strain of A. baumannii studied except the RS-6053. The antimicrobial activity of A3 silver nanoparticle on the RS-307 showed that it is inhibited by the A3 silver nanoparticle (Figure 4). It is very interesting because this strain was reported to have very high resistance to carbapenem $[8,10,12]$. Therefore PVP capped AgNPs can be used for the treatment of this type of high resistance strain. Similarly experiment with RS122 also showed the inhibitory effect of A3 Ag-NPs of this strain (Figure 5). Antimicrobial activity of A3 Ag-NPs was also studied for resistant strain 6694. The result showed that A3 Ag-NPs also have the antimicrobial activity on this strain (Figure 6). It is very interesting to note that resistant strain 6053 has very little inhibitory effect by the A3 Ag-NPs (Figure 7). It also enlighten that resistant strain 6053 might have naturally developed resistance against PVP capped AgNPs.

For selecting the PVP capped AgNPs as a drug of choice against 
Citation: Tiwari V, Khokar MK, Tiwari M, Barala S, Kumar M (2014) Anti-bacterial Activity of Polyvinyl Pyrrolidone Capped Silver Nanoparticles on the Carbapenem Resistant Strain of Acinetobacter baumannii. J Nanomed Nanotechnol 5: 246. doi: 10.4172/2157-7439.1000246

Page 5 of 6

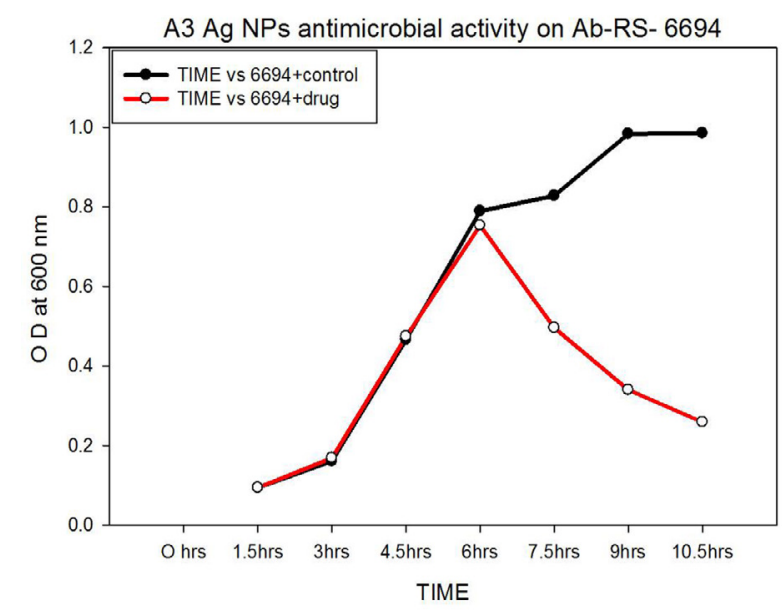

Figure 6: Graphical representation of Antimicrobial activity of A3 Ag-NPs on the resistant strain 6694 of Acinetobacter baumannii.

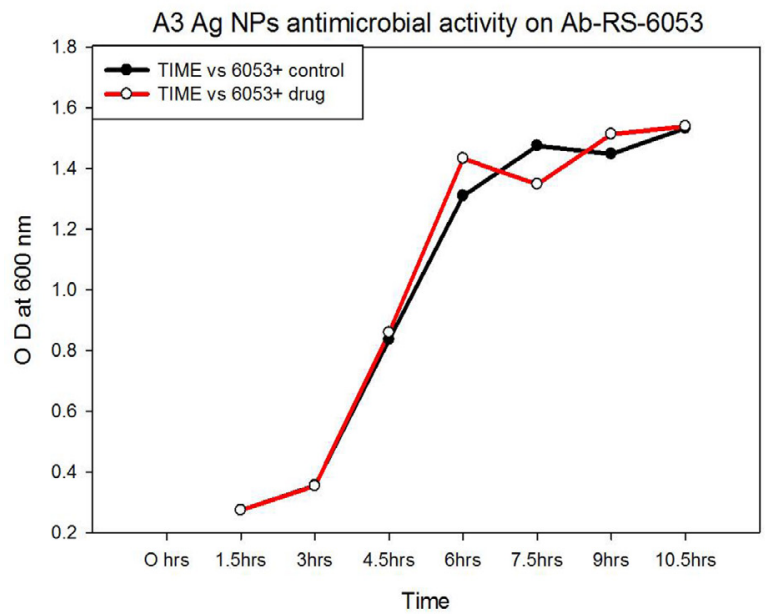

Figure 7: Graphical representation of Antimicrobial activity of A3 Ag-NPs on the resistant strain 6053 of Acinetobacter baumannii.

carbapenem resistance strain of $A$. baumannii, it is also important to know about the toxicity of PVP capped AgNPs on the mammalian cell i.e consumer of AgNPs. Toxicity of the AgNPs is brought via the modulation of reactive oxygen species in cells [41]. Increasing stability of AgNPs may lower toxicity in mammalian cells whilst not reducing their efficacy to fight bacteria which will result in a safer silver nanomaterial [41]. PVP capping on the surface of silver nanoparticles protects from changes in environmental conditions and prevents aggregation [38]. PVP capped Ag-NPs are more stable than citrate-capped AgNPs $[37,38]$ and SDS-capped AgNPs [38] therefore PVP capped AgNPs is less toxic for mammalian cells [41]. Interaction of AgNPs with serum proteins also affects its antimicrobial activity in-vivo. It is also reported that PVP-capped AgNPs showed better antimicrobial activity than citrate capped AgNPs in-vivo [42]. Therefore, PVP-capped AgNPs are more favorable as an alternative drug to carbapenem. PVP-capped AgNPs bind and penetrate the cell wall of Gram-negative bacteria [47] and result into structural change in the cell membrane which could cause an increase in cell permeability, leading to an uncontrolled transport via cytoplasmic membrane which ultimately causes cell death. It is also been proposed that silver nanoparticles also produced free radical- induced membrane damage. Silver ion also have greater tendency to strongly interact with thiol groups of vital enzymes and phosphoruscontaining bases which further damage by interactions with DNA [47]. Therefore, the present study helps in the understanding of the bactericidal effect of PVP-capped AgNPs on carbapenem resistant strain of Acinetobacter baumannii as well as establishment of PVPcapped silver nanomaterial as a drug of choice for the carbapenem resistant strain of Acinetobacter baumannii.

\section{Conclusions}

Carbapenems are the most effective $\beta$-lactam antibiotics that are routinely prescribed by clinicians to patients infected with $A$. baumannii and other Gram negative bacteria. Emergence of resistant strains against carbapenem makes it difficult to treat A. baumannii and is therefore a threat to public health. Polyvinyl pyrrolidone (PVP) capped silver nanoparticles have been prepared which have antimicrobial property against carbapenem resistance strain of Acinetobacter baumannii. Therefore, PVP-capped AgNPs can be developed as an alternative choice to carbapenem, the most effective antibiotic against Acinetobacter baumannii.

\section{Author Contribution}

Conceived and designed the experiments: VT \& MK. Performed the experiments: VT, MK, MKK \& SB. Analyzed the data: VT \& MK. Wrote the paper: MT, VT \& MK.

\section{Acknowledgement}

Dr. Vishvanath Tiwari would like to thanks UGC, India (UGC/BSR/F.No.3018/2014) for Strat Up grant and SERB, DST, India for Start Up grant (SB/YS/LS07/2014)

\section{References}

1. Boucher HW, Talbot GH, Bradley JS, Edwards JE, Gilbert D, et al. (2009) Bad bugs, no drugs: no ESKAPE! An update from the Infectious Diseases Society of America. Clin Infect Dis 48: 1-12.

2. Klevens RM, Edwards JR, Tenover FC, McDonald LC, Horan T, et al. (2006) Changes in the epidemiology of methicillin-resistant Staphylococcus aureus in intensive care units in US hospitals, 1992-2003. Clin Infect Dis 42: 389-391.

3. Davis KA, Moran KA, McAllister CK, Gray PJ (2005) Multidrug-resistant Acinetobacter extremity infections in soldiers. Emerg Infect Dis 11: 1218-1224

4. Kempf M, Bakour S, Flaudrops C, Berrazeg M, Brunel JM, et al. (2012) Rapid detection of carbapenem resistance in Acinetobacter baumannii using matrixassisted laser desorption ionization-time of flight mass spectrometry. PLoS One 7: e31676.

5. Navon-Venezia S, Ben-Ami R, Carmeli Y (2005) Update on Pseudomonas aeruginosa and Acinetobacter baumannii infections in the healthcare setting. Curr Opin Infect Dis 18: 306-313.

6. Bergogne-Bérézin E, Towner KJ (1996) Acinetobacter spp. as nosocomial pathogens: microbiological, clinical, and epidemiological features. Clin Microbiol Rev 9: 148-165

7. Gupta E, Mohanty S, Sood S, Dhawan B, Das BK, et al. (2006) Emerging resistance to carbapenems in a tertiary care hospital in north India. Indian J Med Res 124: 95-98.

8. Tiwari V, Kapil A, Moganty RR (2012) Carbapenem-hydrolyzing oxacillinase in high resistant strains of Acinetobacter baumannii isolated from India. Microb Pathog 53: 81-86.

9. Hawkey PM, Jones AM (2009) The changing epidemiology of resistance. J Antimicrob Chemother 64 Suppl 1: i3-10.

10. Tiwari V, Moganty RR (2014) Conformational stability of OXA-51 î́-lactamase explains its role in carbapenem resistance of Acinetobacter baumannii. J Biomol Struct Dyn 32: 1406-1420.

11. Tiwari V, Vashistt J, Kapil A, Moganty RR (2012) Comparative proteomics of inner membrane fraction from carbapenem-resistant Acinetobacter baumanni with a reference strain. PLoS One 7: e39451. 
Citation: Tiwari V, Khokar MK, Tiwari M, Barala S, Kumar M (2014) Anti-bacterial Activity of Polyvinyl Pyrrolidone Capped Silver Nanoparticles on the Carbapenem Resistant Strain of Acinetobacter baumannii. J Nanomed Nanotechnol 5: 246. doi: 10.4172/2157-7439.1000246

12. Tiwari V, Nagpal I, Subbarao N, Moganty RR (2012) In-silico modeling of a novel OXA-51 from $\hat{i}^{2}$-lactam-resistant Acinetobacter baumannii and its interaction with various antibiotics. J Mol Model 18: 3351-3361.

13. Vashist J, Tiwari V, Das R, Kapil A, Rajeswari MR (2011) Analysis of penicillinbinding proteins (PBPs) in carbapenem resistant Acinetobacter baumannii. Indian J Med Res 133: 332-338.

14. Vashist J, Tiwari V, Kapil A, Rajeswari MR (2010) Quantitative profiling and identification of outer membrane proteins of beta-lactam resistant strain of Acinetobacter baumannii. J Proteome Res 9: 1121-1128.

15. Tiwari V, Tiwari M (2014) Quantitative proteomics to study carbapenem resistance in Acinetobacter baumannii. Front Microbiol 5: 512

16. Tiwari $\vee(2014)$ Differential proteomics has emerged as a tool to understand carbapenem resistance in Acinetobacter baumannii. Journal of Integrated Omics 4: 1-2.

17. Tiwari V, Moganty RR (2013) Structural studies on New Delhi Metallo- $\hat{I}^{2}$ lactamase (NDM-2) suggest old $\hat{I}^{2}$-lactam, penicillin to be better antibiotic for NDM-2-harbouring Acinetobacter baumanni. J Biomol Struct Dyn 31: 591-601.

18. Tiwari V, Rajeswari MR (2013) Effect of Iron Availability on the Survival of Carbapenem-Resistant Acinetobacter baumannii: a Proteomic Approach. Journal of Proteomics \& Bioinformatics 06: 125-131.

19. Sengstock DM, Thyagarajan R, Apalara J, Mira A, Chopra T, et al. (2010) Multidrug-resistant Acinetobacter baumannii: an emerging pathogen among older adults in community hospitals and nursing homes. Clin Infect Dis 50: 1611-1616.

20. Jamulitrat S, Arunpan P, Phainuphong P (2009) Attributable mortality of imipenem-resistant nosocomial Acinetobacter baumannii bloodstream infection. J Med Assoc Thai 92: 413-419.

21. Losasso C, Belluco S, Cibin V, Zavagnin P, Micetic I, et al. (2014) Antibacteria activity of silver nanoparticles: sensitivity of different Salmonella serovars. Front Microbiol 5: 227

22. Kumar M, Reddy GB (2009) Ag:ZrO2 nanocomposite thin films derived using a novel sol-gel technique. physica status solidi (b) 246: 2232-2237.

23. Kumar M, Sandeep CSS, Kumar G, Mishra YK, Philip R, et al. (2013) Plasmonic and Nonlinear Optical Absorption Properties of Ag:ZrO2 Nanocomposite Thin Films. Plasmonics 9: 129-136.

24. Kumar M, Kulriya PK, Pivin JC, Avasthi DK (2011) Evolution and tailoring of plasmonic properties in $\mathrm{Ag}: \mathrm{ZrO} 2$ nanocomposite films by swift heavy ion irradiation. Journal of Applied Physics 109: 044311.

25. Singh UB, Agarwal DC, Khan SA, Kumar M, Tripathi A, et al. (2011) Engineering of hydrophilic and plasmonic properties of $\mathrm{Ag}$ thin film by atom beam irradiation. Applied Surface Science 258: 1464-1469.

26. Kumar M, Parashar KK, Tandi SK, Kumar T, Agarwal DC, et al. (2013) Fabrication of Ag:TiO2 Nanocomposite Thin Films by Sol-Gel Followed by Electron Beam Physical Vapour Deposition Technique. Journal of Spectroscopy 2013: 1-6.

27. Kumar M, Reddy GB (2010) Effect of atmospheric exposure on the growth of citrate-capped silver nanoparticles. Physica E: Low-dimensional Systems and Nanostructures 42: 1940-1943.

28. Niakan S, Niakan M, Hesaraki S, Nejadmoghaddam MR, Moradi M, et al. (2013) Comparison of the Antibacterial Effects of Nanosilverwith18 Antibiotics on Multidrug Resistance Clinical Isolates of Acinetobacter baumannii. Jundishapur Journal of Microbiology 6 .

29. Kawashita M, Tsuneyama S, Miyaji F, Kokubo T, Kozuka H, et al. (2000) Antibacterial silver-containing silica glass prepared by sol-gel method. Biomaterials 21: 393-398

30. Anas A, Jiya J, Rameez MJ, Anand PB, Anantharaman MR, et al. (2013) Sequential interactions of silver-silica nanocomposite (Ag-SiO2 NC) with cell wall, metabolism and genetic stability of Pseudomonas aeruginosa, a multiple antibiotic-resistant bacterium. Lett Appl Microbiol 56: 57-62.

31. Kim YH, Lee DK, Cha HG, Kim CW, Kang YS (2007) Synthesis and Characterization of Antibacterial Ag-SiO2 Nanocomposite. The Journal of Physical Chemistry C 111: 3629-3635

32. Birla SS, Tiwari VV, Gade AK, Ingle AP, Yadav AP, et al. (2009) Fabrication of silver nanoparticles by Phoma glomerata and its combined effect against
Escherichia coli, Pseudomonas aeruginosa and Staphylococcus aureus. Lett Appl Microbiol 48: 173-179.

33. Avinash Ingle, Aniket Gade, Sebastien Pierrat, Sonnichsen C, Rai M (2008) Mycosynthesis of Silver Nanoparticles Using the Fungus Fusarium acuminatum and its Activity Against Some Human Pathogenic Bacteria. Current Nanoscience 4: 141-144

34. Li X, Xu H, Chen ZS, Chen G (2011) Biosynthesis of Nanoparticles by Microorganisms and Their Applications. Journal of Nanomaterials 2011:1-16.

35. Huang L, Dai T, Xuan Y, Tegos GP, Hamblin MR (2011) Synergistic combination of chitosan acetate with nanoparticle silver as a topical antimicrobial: efficacy against bacterial burn infections. Antimicrob Agents Chemother 55: 3432-3438

36. Flores CY, Miñán AG, Grillo CA, Salvarezza RC, Vericat C, et al. (2013) Citratecapped silver nanoparticles showing good bactericidal effect against both planktonic and sessile bacteria and a low cytotoxicity to osteoblastic cells. ACS Appl Mater Interfaces 5: 3149-3159.

37. Hu Zhang, Zhang C (2014) Transport of silver nanoparticles capped with different stabilizers in water saturated porous media. Journal of Materials and Environmental Science 5: 231-236.

38. Kora AJ, Rastogi L (2013) Enhancement of antibacterial activity of capped silver nanoparticles in combination with antibiotics, on model gram-negative and gram-positive bacteria. Bioinorg Chem Appl 2013: 871097.

39. El Badawy AM, Luxton TP, Silva RG, Scheckel KG, Suidan MT, et al. (2010) Impact of environmental conditions ( $\mathrm{pH}$, ionic strength, and electrolyte type) on the surface charge and aggregation of silver nanoparticles suspensions. Environ Sci Technol 44: 1260-1266.

40. Hitchman A, Smith GH, Ju-Nam Y, Sterling M, Lead JR (2013) The effect of environmentally relevant conditions on PVP stabilised gold nanoparticles. Chemosphere 90: 410-416.

41. Setyawati MI, Yuan X, Xie J, Leong DT (2014) The influence of lysosomal stability of silver nanomaterials on their toxicity to human cells. Biomaterials 35: 6707-6715.

42. Gnanadhas DP, Ben Thomas M, Thomas R, Raichur AM, Chakravortty D (2013) Interaction of silver nanoparticles with serum proteins affects thei antimicrobial activity in vivo. Antimicrob Agents Chemother 57: 4945-4955.

43. Landelle C, Legrand P, Lesprit P, Cizeau F, Ducellier D, et al. (2013) Protracted outbreak of multidrug-resistant Acinetobacter baumannii after intercontinental transfer of colonized patients. Infect Control Hosp Epidemiol 34: 119-124.

44. Dipak Kumar Bhui, Harekrishna Bar, Priyanka Sarkar, Gobinda Prasad Sahoo, Sankar Prasad De, et al. (2009) Synthesis and UV-Vis spectroscopic study of silver nanoparticles in aqueous SDS solution. Journal of Molecular Liquids 145: 33-37.

45. Gasaymeh SS, Radiman S, Heng LY, Saion E, GHM S (2010) Synthesis and Characterization of Silver/Polyvinilpirrolidone (Ag/PVP) Nanoparticles Using Gamma Irradiation Techniques. American Journal of Applied Sciences 7: 892-901.

46. Kumar M, Reddy GB (2010) Tailoring surface plasmon resonance in Ag:ZrO2 nanocomposite thin films. Physica E: Low-dimensional Systems and Nanostructures 43: 470-474.

47. Morones JR, Elechiguerra JL, Camacho A, Holt K, Kouri JB, et al. (2005) The bactericidal effect of silver nanoparticles. Nanotechnology 16: 2346-2353. 